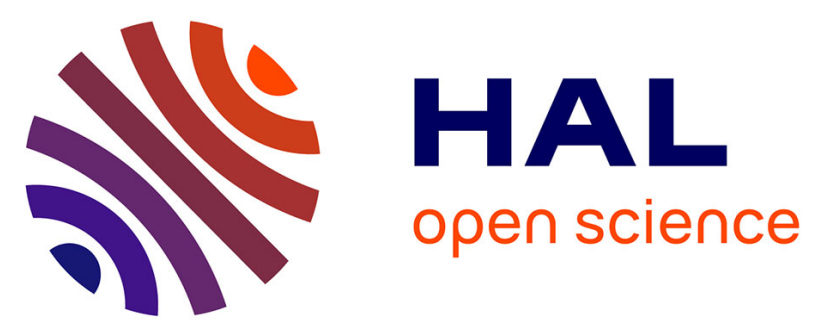

\title{
Early Hepatic Artery Thrombosis After Liver Transplantation: What is the Impact of the Arterial Reconstruction Type?
}

Astrid Herrero, Regis Souche, Emmanuel Joly, Gildas Boisset, Hussein Habibeh, Hassan Bouyabrine, Fabrizio Panaro, José Ursic-Bedoya, Samir Jaber, Boris Guiu, et al.

\section{To cite this version:}

Astrid Herrero, Regis Souche, Emmanuel Joly, Gildas Boisset, Hussein Habibeh, et al.. Early Hepatic Artery Thrombosis After Liver Transplantation: What is the Impact of the Arterial Reconstruction Type?. World Journal of Surgery, 2017, 41 (8), pp.2101 - 2110. 10.1007/s00268-017-3989-4 . hal01774050

\author{
HAL Id: hal-01774050 \\ https://hal.science/hal-01774050
}

Submitted on 16 Dec 2019

HAL is a multi-disciplinary open access archive for the deposit and dissemination of scientific research documents, whether they are published or not. The documents may come from teaching and research institutions in France or abroad, or from public or private research centers.
L'archive ouverte pluridisciplinaire HAL, est destinée au dépôt et à la diffusion de documents scientifiques de niveau recherche, publiés ou non, émanant des établissements d'enseignement et de recherche français ou étrangers, des laboratoires publics ou privés. 


\title{
Early Hepatic Artery Thrombosis After Liver Transplantation: What is the Impact of the Arterial Reconstruction Type?
}

\author{
Astrid Herrero $^{1} \cdot$ Regis Souche $^{1} \cdot$ Emmanuel Joly $^{1} \cdot$ Gildas Boisset $^{1} \cdot$ \\ Hussein Habibeh $^{1} \cdot$ Hassan Bouyabrine ${ }^{1}$. Fabrizio Panaro ${ }^{1} \cdot$ Jose Ursic-Bedoya $^{2}$. \\ Samir Jaber ${ }^{3} \cdot$ Boris Guiu $^{4} \cdot$ Georges Philippe Pageaux ${ }^{2} \cdot$ Francis Navarro $^{1}$
}

\begin{abstract}
Objective Hepatic artery thrombosis (HAT) is the most severe vascular complication occurring after liver transplantation, with an incidence ranging from 2 to $9 \%$ in adults. Although the ideal arterial reconstruction is often described as a short and non-redundant anastomosis fashioned between the recipient and donor hepatic arteries, there is no strong evidence about this ideal reconstruction in the literature. The aim of this study was to assess the impact of the type of arterial reconstruction on early HAT after primary liver transplantation.

Methods We retrospectively reviewed a contemporary MELD era cohort of 282 patients who underwent deceased donor primary liver transplantation from 2007 to 2012. Graft artery was classified as "short" when the section was located at the proper/common hepatic artery or "long" when the celiac trunk was used for anastomosis. Recipient arterial sites for arterial anastomosis were classified in three sites: (1) "distal" (proper hepatic artery or common hepatic artery/gastro-duodenal bifurcation), (2) "intermediate" (common hepatic artery) and (3) "proximal" (celiac trunk-splenic artery-aorta). We used univariate and multivariate analyses to assess the impact of different types of arterial reconstruction on early HAT.

Results Of 282 primary liver transplantations, 17 patients $(6 \%)$ developed early HAT. Patients with and without early HAT had comparable demographic and operative data. The main anastomotic combination was short graft artery on the recipient-common hepatic artery $(n=111,39 \%)$. A long graft artery was used in 91 patients $(32 \%)$ and was associated with hepatic artery variations $(56 \% ; n=51 ; p=0.001)$. Arterial reconstructions using a long graft artery $(p=0.003)$, a recipient proximal site as celiac trunk-splenic artery-aorta $(p=0.02)$ and the combination of a long graft artery on the recipient distal hepatic artery $(p=0.02)$ were significantly associated with early HAT. The early HAT rate in patients with a long graft artery was not significantly different between patients with or without donor arterial variation (respectively, $12 \%(n=6 / 51)$ vs. $12 \%(n=5 / 40) ; p=1)$. In multivariate analysis, the use of a long graft artery, whatever the recipient anastomosis site, was an independent risk factor of early HAT (OR 3.2; 95\% CI 1.2-9; $p=0.02$ ).

Conclusion The type of arterial reconstruction used for arterial anastomosis during primary liver transplantation has an impact on the occurrence of early HAT. The use of a long graft artery is an independent risk factor of early HAT. Thereby, we recommend the use of a short graft artery with a direct path when feasible to reduce the occurrence of early HAT after primary liver transplantation.
\end{abstract}

Astrid Herrero

a-herrero@chu-montpellier.fr

Liver Transplant Unit, Department of Digestive Surgery and Liver Transplantation, Hopital Saint Eloi - Hopitaux

Universitaires de Montpellier, University of Montpellier, 80, Avenue Augustin Fliche, 34295 Montpellier Cedex 5, France
2 Liver Transplant Unit, Department of Hepatology and Liver Transplantation, Hopital Saint Eloi - Hopitaux Universitaires de Montpellier, University of Montpellier, 80, Avenue Augustin Fliche, 34295 Montpellier Cedex 5, France 


\section{Abbreviations}

$\begin{array}{ll}\text { A } & \text { Aorta } \\ \text { AA } & \text { Arterial anastomosis } \\ \text { CHA } & \text { Common hepatic artery } \\ \text { CT } & \text { Celiac trunk } \\ \text { CT scan } & \text { Computed tomography scan } \\ \text { GDA } & \text { Gastroduodenal artery } \\ \text { GS } & \text { Graft survival } \\ \text { HA } & \text { Hepatic artery } \\ \text { HAT } & \text { Hepatic artery thrombosis } \\ \text { ICU } & \text { Intensive care unit } \\ \text { LT } & \text { Liver transplantation } \\ \text { MELD } & \text { Model for end-stage liver disease } \\ \text { OS } & \text { Overall survival } \\ \text { PHA } & \text { Proper hepatic artery } \\ \text { RRHA } & \text { Replaced right hepatic artery } \\ \text { SA } & \text { Splenic artery } \\ \text { SMA } & \text { Superior mesenteric artery } \\ \text { TACE } & \text { Transarterial chemoembolization } \\ \text { POD } & \text { Postoperative day }\end{array}$

\section{Introduction}

Liver transplantation (LT) is a life-saving treatment for patients with end-stage liver disease, acute liver failure or hepatocellular carcinoma [1-4]. Vascular complications after LT increase postoperative morbidity and contribute to subsequent primary graft dysfunction, ischemic biliary complications and long-term graft loss [5-7]. Hepatic artery thrombosis (HAT) is the most severe vascular complication with an incidence ranging from 2 to $9 \%$ in adults [6-11]. Anatomical or technical causes of early HAT occurring within 1 month after LT remain unclearly identified. Although Dokmak et al. [12] described the ideal arterial reconstruction as a short and non-redundant anastomosis fashioned between the recipient and donor hepatic arteries, there is no strong evidence about this ideal reconstruction in the literature. In deceased donor LT, arterial anastomosis (AA) depends on a combination of donor and recipient artery diameters, vessel quality, donor/recipient anatomical variations and specific conditions related to the indication

Liver Transplant Unit, Department of Anesthesiology, Intensive Care and Transplantation Unit, Hopital Saint Eloi Hopitaux Universitaires de Montpellier, University of Montpellier, 80, Avenue Augustin Fliche,

34295 Montpellier Cedex 5, France

4 Liver Transplant Unit, Department of Radiology, Hopital Saint Eloi - Hopitaux Universitaires de Montpellier, University of Montpellier, 80, Avenue Augustin Fliche, 34295 Montpellier Cedex 5, France for LT. We purposed to describe and analyze these combinations using a simple classification for donor and recipient sites used for arterial anastomosis. The aim of this study was to clarify the impact of the type of arterial reconstruction on early HAT occurrence after primary LT involving whole organ graft in a contemporary model for end-stage liver disease (MELD) cohort.

\section{Patients and methods}

\section{Study definition}

We analyzed a prospectively maintained database of 338 patients undergoing liver transplantation at the University of Montpellier teaching hospital (France) from January 1, 2007, to October 31, 2012. Monitoring was carried out until December 2014 with a median follow-up of 39 months (range: 32-630 months). All liver grafts were from deceased donors. Patient with primary LT involving whole organ graft was included in this study. Patients with (1) LT before the study period and retransplantation during the study period, (2) requiring arterial conduit (donor iliac artery, vein interposition, prosthetic grafts), (3) primary graft non-function or (4) split liver transplantation were excluded. Results of arterial reconstruction after retransplantation for included patients were not analyzed. The main criterion was early HAT occurring within 1 month post-LT, defined as a lack of arterial flow determined by Doppler ultrasound and confirmed by a computed tomography scan (CT scan). Preoperative evaluation, surgical data, postoperative complications, 90-day mortality and hospital stay were recorded. Arterial reconstructions during retransplantation were not analyzed, and patients with missing data $>5 \%$ were excluded.

\section{Preoperative evaluation, surgery and follow-up}

After a preoperative visit including a CT scan, all cases were discussed in the multidisciplinary transplantation meeting to assess the arterial anatomy of the recipient and discuss technical options. As recommended, the patency and size of the hepatic artery (HA) as well as the identification of any variation that could result in reduced flow of the HA were systematically analyzed with a radiologist [13, 14].

Donor liver recovery was done by four experienced fellows with the no arterial touch technique and dissection of the arteries on back-table $[15,16]$. Preservation of the donor livers was done using the IGL ${ }^{\circledR}$ (Waters medical systems, USA), Celsior ${ }^{\circledR}$ (Genzyme Polyclonas S.A.S., France) or Viaspan ${ }^{\circledR}$ (Bristol-Myers Squibb, USA) solutions in 76, 19 and 5\%, respectively. 
In case of donor arterial variations, senior surgeons performed back-table reconstruction if required. Donor's right hepatic artery variation (Type III and IV) was reconstructed using Gordon technique, anastomosis with either donor gastroduodenal artery or splenic artery $[17,18]$. These three types of reconstruction were defined as a complex arterial reconstruction. A replaced left hepatic artery did not justify reconstruction and was managed with an anastomosis between a Carrel patch of donor celiac trunk and recipient artery [18].

Most liver transplantations were performed using piggyback surgical technique under this sequence: (1) a caval anastomosis (latero-lateral, three-vein technique [19] or endto-end), (2) an end-to-end portal anastomosis, (3) an arterial anastomosis and (4) a duct-to-duct biliary anastomosis. No porto-caval shunt was used. A sequential revascularization was done, and the graft was first perfused via the portal vein and then via the hepatic artery. In our protocol, recipients received anti-thrombin III to maintain the anti-thrombin rate above $70 \%$ in the first postoperative days. In addition to systematic intermittent compression stockings, in the absence of any hemorrhagic complications and/or low platelet count $<50000 \mathrm{ml}$, all patients received heparin to maintain an activated partial thromboplastin time at 1.5-2.0 fold the baseline value and later substituted with prophylactic low molecular weight heparin. Acetylsalicylic acid was reserved for elderly donors (age $>70$ year old), patients with atheromatosis, small arteries (diameter $<5 \mathrm{~mm}$ ) and/ or complex arterial reconstruction [20].

Postoperative arterial patency was examined by Doppler ultrasound during the first week at postoperative days 1, 3 and 5 routinely. Subsequent examinations were carried out as indicated clinically.

\section{The arterial anastomosis}

The arterial reconstruction was planned before the transplantation to reduce prolonged warm ischemia (number, size and quality of the donor and recipient arteries). The flow of the recipient HA was evaluated by observation and pulse palpation after the total hepatectomy. In case of inadequate HA flow (small hepatic artery, intraoperative intimal dissection, mass ligation of hepatic pedicles in patients with portal cavernoma), dissection of the common hepatic artery (CHA) and then of the recipient celiac trunk (CT) was performed to determine the future site of arterial anastomosis (AA). On a case-by-case basis, an adapted and oriented arterial anastomosis with intima-to-intima opposition was fashioned under a surgical loop with a running or separated 6-0 or 7-0 polypropylene suture. When arterial reconstruction was redundant with a long conduit, omental flap or interposition of hemostatic sealants was used to prevent arterial kinking.

\section{Definition of graft artery length and recipient arterial sites}

Graft artery length was prospectively defined as "short" when the section was located at the common hepatic artery or "long" when the celiac trunk was used for anastomosis (Carrel patch [17]). In cases of donor right hepatic artery, the Gordon technique or a reconstruction using donor splenic artery was considered as a long graft artery. On the other hand, a reconstruction using donor gastroduodenal artery resulted in a short graft artery.

Recipient arterial sites for AA were classified in three sites: (1) proper hepatic artery or common hepatic artery/gastro-duodenal bifurcation (PHA or CHA/GDA bifurcation = distal site), (2) common hepatic artery ( $\mathrm{CHA}=$ intermediate site) and (3) celiac trunk-splenic artery-aorta (CT-SA-A = proximal site).

All the arterial anastomoses were therefore classified according to 6 types of arterial reconstruction.

\section{Statistical analysis}

Variables were compared between patients with and without early HAT with Chi-square test, Fisher's exact test or Student's $t$ test, as appropriate. All variables with $p<0.10$ in univariate analysis were studied in a multiple logistic regression model. A $p$ value less than 0.05 was considered as statistically significant. Patient overall survival (OS) and graft survival (GS) were calculated with the Kaplan-Meier method. Survival was compared between groups using the log-rank test. Statistical analyses were performed using SPSS Statistics, version 20.0, for Macintosh (IBM Corp, Armonk, NY) and GraphPad Prism, version 5.00, for Windows (GraphPad Software, San Diego, CA).

\section{Results}

\section{Demographic and operative data}

During the study period, 282 patients with primary liver transplantation involving whole organ graft were included. The recipients were 212 men and 70 women, with a mean age of 53 years (range 17-76). Patient characteristics and comorbidities are detailed in Table 1 . Prominent indications were (1) alcoholic liver disease in $56.4 \%$, (2) viral hepatitis in $27 \%$ and (3) non-alcoholic liver steatohepatitis in $8 \%$ of patients. Hepatocellular carcinoma was present in 105 patients $(37.2 \%)$, and 52 of them $(18 \%)$ had been treated by transarterial chemoembolization before LT (1-3 treatments per patients). Patients were Child-Pugh score A, $\mathrm{B}$ or $\mathrm{C}$ in 19, 22 and 54\%, respectively. The median MELD 
Table 1 Pretransplant recipient characteristics

\begin{tabular}{|c|c|c|c|c|}
\hline Variables & Patients & HAT $n(\%)$ & No HAT $n(\%)$ & $P$ value \\
\hline Number of LTs, $n$ & 282 & 17 & 265 & \\
\hline \multicolumn{5}{|l|}{ Demographics } \\
\hline Age (year) median $\pm \mathrm{SD}$ & $53 \pm 10$ & $48 \pm 10$ & $54 \pm 10.5$ & 0.06 \\
\hline Sex, male, $n(\%)$ & $212(75)$ & $14(82)$ & $198(74)$ & 0.48 \\
\hline \multicolumn{5}{|l|}{ Comorbidities } \\
\hline BMI, $\mathrm{kg} / \mathrm{m}^{2}$, median $\pm \mathrm{SD}$ & $25 \pm 4$ & $24 \pm 3$ & $25 \pm 4$ & 0.10 \\
\hline Hypertension, $n(\%)$ & $68(24)$ & $2(11)$ & $66(25)$ & 0.22 \\
\hline Diabetes, $n(\%)$ & $48(17)$ & $1(6)$ & $47(18)$ & 0.20 \\
\hline Chronic renal failure, $n(\%)$ & $16(6)$ & $3(18)$ & $13(5)$ & 0.06 \\
\hline Coronary artery disease, $n(\%)$ & $34(12)$ & $0(0)$ & $34(13)$ & 0.23 \\
\hline Earlier susmesocolic operation, $n(\%)$ & $53(19)$ & $3(18)$ & 50 (19) & 0.93 \\
\hline \multicolumn{5}{|l|}{ Pretransplant acuity } \\
\hline MELD, median $\pm \mathrm{SD}$ & $20 \pm 10$ & $25 \pm 11$ & $20 \pm 10$ & 0.12 \\
\hline Child A, $n(\%)$ & $54(19)$ & $4(24)$ & $50(19)$ & 0.74 \\
\hline Child B, $n(\%)$ & $62(22)$ & $3(18)$ & $59(22)$ & 1 \\
\hline Child C, $n(\%)$ & $153(54)$ & $9(53)$ & $144(54)$ & 0.91 \\
\hline \multicolumn{5}{|l|}{ UNOS status } \\
\hline No hospitalized & $187(66)$ & $8(47)$ & $179(66)$ & 0.08 \\
\hline Conventional hospitalization & $43(15)$ & $5(30)$ & $38(14)$ & 0.15 \\
\hline ICU hospitalization & $52(18)$ & $4(24)$ & $48(18)$ & 0.52 \\
\hline \multicolumn{5}{|l|}{ Causes of liver disease, $n(\%)$} \\
\hline Viral hepatitis & $75(27)$ & $5(30)$ & $70(26)$ & 0.78 \\
\hline ALD & $159(56)$ & $11(65)$ & $148(56)$ & 0.61 \\
\hline NASH & $22(8)$ & $2(11)$ & $20(8)$ & 0.95 \\
\hline Acute liver failure & $9(3)$ & $0(0)$ & $9(3)$ & 1 \\
\hline $\mathrm{PBC} / \mathrm{PSC}$ & $21(7)$ & $3(18)$ & $18(7)$ & 0.13 \\
\hline Other & $29(10)$ & $0(0)$ & $29(11)$ & 0.23 \\
\hline Hepatocellular carcinoma, $n,(\%)$ & $105(37)$ & $8(47)$ & $97(37)$ & 0.98 \\
\hline Pretransplant TACE & $52(18)$ & $3(18)$ & 49 (18) & 1 \\
\hline
\end{tabular}

$H A T$ hepatic artery thrombosis, $L T$ liver transplantation, $B M I$ body mass index, $M E L D$ model for end-stage liver disease, $I C U$ intensive care unit, $A L D$ alcoholic liver disease, NASH non-alcoholic steatohepatitis, PBC primary biliary cirrhosis, PSC primary sclerosing cholangitis, TACE transarterial chemoembolization

score was 20 (range: 6-46). Before LT, according to the UNOS Criteria, patients were discharged, hospitalized or in ICU in 66,15 and $18 \%$ of cases, respectively. Donor characteristics and operative data are detailed in Table 2.

\section{Arterial anatomy and types of reconstruction}

Graft arterial anatomy was classic (Type I) in 206 patients (73\%). We found donor arterial variations in 76 patients (27\%): a replaced left hepatic artery (RLHA; Type II) in 25 patients $(9 \%)$, a replaced right hepatic artery (RRHA; Type III) in 35 patients (13\%), replaced left and right arteries (Type IV) in 13 patients (4\%) and a CHA from SMA (Type $\mathrm{V})$ in three patients $(1 \%)$.
The length of graft artery was mainly short $(68 \%$, $n=191)$.

In recipients, used sites were intermediate $(\mathrm{CHA})$ in $61 \%(n=172)$, distal (PHA or CHA/GDA bifurcation) in $35 \%(n=98)$ and proximal (CT-SA-A) in $4 \%$ with inadequate HA flow $(n=12)$ of patients.

Most common reconstructions were short graft artery on the recipient CHA ( $n=111,39 \%)$, short graft artery on recipient "PHA or CHA/GDA bifurcation" ( $n=74,26 \%)$, long graft artery on CHA $(n=61,22 \%)$ and long graft artery on "PHA or CHA/GDA bifurcation" $(n=24,9 \%)$.

A long graft artery was used in 91 patients (32\%). These long graft arteries resulted from arterial variations in 51 cases $(56 \%)$ requiring (1) a complex reconstruction in 26 
Table 2 Donor and operative data

\begin{tabular}{|c|c|c|c|c|}
\hline Variables & $\begin{array}{l}\text { Patients }(n=282) \\
n(\%)\end{array}$ & $\begin{array}{l}\text { HAT }(n=17) \\
n(\%)\end{array}$ & $\begin{array}{l}\text { No HAT }(n=265) \\
n(\%)\end{array}$ & $p$ value \\
\hline \multicolumn{5}{|l|}{ Donor characteristics } \\
\hline Age (year) median \pm SD & $52 \pm 15$ & $49 \pm 13$ & $52 \pm 15$ & 0.60 \\
\hline$<70$ year old & $234(83)$ & $14(82)$ & $220(83)$ & - \\
\hline$>70$ year old & $48(17)$ & $3(18)$ & 45 (17) & 0.74 \\
\hline Sex, male, $n(\%)$ & $172(61)$ & $10(59)$ & $162(61)$ & 0.84 \\
\hline BMI $\left(\mathrm{kg} / \mathrm{m}^{2}\right)$ median $\pm \mathrm{SD}$ & $25 \pm 4$ & $25 \pm 4$ & $25 \pm 6$ & 0.49 \\
\hline \multicolumn{5}{|l|}{ Operative characteristics } \\
\hline CIT $(\min )$ median $\pm \mathrm{SD}$ & $452 \pm 116$ & $480 \pm 112$ & $450 \pm 117$ & 0.31 \\
\hline WIT (min) median \pm SD & $65 \pm 28$ & $73 \pm 22$ & $67 \pm 27$ & 0.48 \\
\hline Transfusion (U) median \pm SD & $7 \pm 4$ & $8 \pm 4$ & $7 \pm 4$ & 0.68 \\
\hline Fresh frozen plasma \pm SD & $8 \pm 6$ & $9 \pm 6$ & $8 \pm 6$ & 0.57 \\
\hline \multicolumn{5}{|l|}{ Biliary reconstructions } \\
\hline Choledochocholedochostomy & $257(91)$ & $15(88)$ & $242(91)$ & - \\
\hline Roux-en-Y choledochojejunostomy & $25(8)$ & $2(12)$ & $23(9)$ & 0.64 \\
\hline $\mathrm{T}$ tube & $70(24)$ & $6(35)$ & $64(24)$ & 0.30 \\
\hline
\end{tabular}

HAT hepatic artery thrombosis, BMI body mass index, CIT cold ischemia time, WIT warm ischemia time

patients by Gordon technique $(n=13)$ or an anastomosis between a replaced right hepatic artery and donor SA $(\mathrm{n}=13)$, (2) a Carrel patch of CT $(n=25)$.

A Carrel patch of CT was performed in 40 cases (44\%) with classic donor arterial anatomy according to the surgeon habit or recognition of small donor arteries $(<5 \mathrm{~mm})$.

Arterial anatomy and types of reconstruction are detailed in Table 3.

Acetylsalicylic acid therapy was introduced intraoperatively in 114 patients $(40 \%)$ conforming to the surgical team recommendation due to complex arterial reconstruction $(n=37,32 \%)$, atheromatosis $(n=33,29 \%)$, elderly donors $(n=24,21 \%)$ and/or patients with small arteries $(n=20,18 \%)$.

\section{Incidence and presentation of HAT}

Early HAT was diagnosed in $17(6 \%)$ of the 282 patients with LT with a median delay of 3 days after LT (range: $1-25)$. Late HAT occurred in $2 \%$ of patients $(n=6)$ with a median delay of 191 days (range: 65-223). Presentation of early HAT included elevated transaminases in $73 \%$ of cases, biliary complications in $18 \%$, fever and sepsis in $7 \%$ and graft dysfunction or failure in $5 \%$.

\section{Management of early HAT, outcomes and survival analysis}

Of the 17 patients with early HAT, 11 patients underwent surgical treatment with thrombectomy and re-anastomosis,
4 patients received medical treatment (acetylsalicylic therapy $(n=3)$, endovascular treatment with a stent $(n=1))$ and two patients underwent retransplantation (at POD 7 and 21). The ninety-day mortality of patients with early HAT was $23 \%(n=4$, one patient with surgical treatment, one patient with reLT and two patients with medical treatment). Early HAT increased significantly recipient mortality $(\mathrm{HR}=3.88 ; 95 \%$ CI $3.38-46.54$; $p=0.0002)$ and graft loss $(\mathrm{HR}=5.85 ; 95 \%$ CI $2.37-90$; $p=0.01)$ as shown in Figs. 1, 2, respectively.

\section{Analysis of risk factors of early HAT}

Demographic and operative data of patients with and without early HAT are compared in Tables 1, 2, respectively. No difference was found concerning donor/recipient age, donor/recipient gender, comorbidities, UNOS criteria, causes of liver disease, previous transarterial chemoembolization and surgeon.

Types of arterial reconstruction and their results are described in Fig. 3 and Table 3. Concerning the length of the graft artery, the rate of early HAT was greater with a long graft artery than with a short graft artery (12\% vs. $3 \%$; $p=0.003$ ).

Although donor arterial variation $(56 \%(n=51 / 91)$ vs. $14 \%(25 / 191), p=0.001)$ and complex reconstruction (29\% $(n=26 / 91)$ vs. $12 \%(22 / 191), p=0.006)$ were significantly associated with a long graft artery compared to short graft artery, these two variables were not significantly associated with early HAT (respectively, $p=0.08$ 
Table 3 Arterial anatomy, types of reconstruction and HAT prevention

Variables Patients $(n=282)$

Patients $(n=282)$

$n(\%)$

HAT $(n=17)$

$n(\%)$

No HAT $(n=265)$

$p$ value

Donor arterial anatomy

Classic (Type I)

$206(73)$
$76(27)$
$25(9)$
$35(13)$
$13(4)$
$3(1)$

$10(59)$

7 (41)

$n(\%)$

Variations

Replaced left hepatic artery (Type II)

3 (18)

1 (6)

Replaced right hepatic artery (Type III)

2 (12)

Replaced right and left arteries (Type IV)

CHA from SMA (Type V)

1 (6)

96 (74)

69 (26)

0.08

22 (8)

0.67

34 (13)

0.11

11 (4)

0.34

2 (1)

0.25

Donor artery length

Short

191 (68)

6 (35)

185 (70)

$91(32)$

11 (65)

$80(30)$

$-$

Long

98 (35)

5 (30)

93 (35)

0.003

Recipient sites

PHA or CHA-GDA bifurcation

$172(61)$

9 (53)

12 (4)

3 (18)

0.79

CT/SA/Aorta

Anastomotic combinations

\section{Short}

PHA or CHA-GDA bifurcation

74 (26)

111 (39)

6 (2)

CT/SA/Aorta

Long

PHA or CHA-GDA bifurcation

CHA

CT/SA/Aorta

Donor small arteries $(<5 \mathrm{~mm})$

No

Yes

Complex arterial reconstruction*

No

Yes

Gordon

RRHA on donor GDA

RRHA on donor SA

Arterial kinking prevention

No

Yes

Omental flap

Hemostatic sealant

Postoperative acetylsalicylic acid therapy
No
$168(60)$
Yes
$114(40)$

1 (6)

4 (24)

1 (6)

4 (23)

5 (30)

2 (12)

$14(82)$

3 (18)

$14(82)$

3 (18)

2 (12)

1 (6)

$0(0)$

15 (89)

2 (18)

1 (6)

1 (6)

8 (47)

9 (53)
163 (62)

9 (3)

0.48

0.02

73 (28)

107 (40)

5 (2)

0.64

0.14

20 (8)

0.02

56 (21)

0.26

4 (2)

0.57

248 (94)

17 (6)

0.08

$220(87)$

45 (13)

0.98

11 (4)

0.20

21 (8)

0.99

13 (5)

0.99

191 (72)

74 (28)

0.14

64 (24)

0.12

10 (4)

0.83

160 (60)

105 (40)
0.31

HAT hepatic artery thrombosis, CHA common hepatic artery, SMA superior mesenteric artery, PHA proper hepatic artery, GDA gastroduodenal artery, $C T$ celiac trunk, $S A$ splenic artery, RRHA replaced right hepatic artery

* More than 1 arterial anastomosis (Gordon: end-to-end anastomosis between SMA and CT during back-table)

and $p=0.98$ ). The early HAT rate in patients with a long graft artery was not significantly different between LT with or without donor arterial variation (respectively, 12\% $(n=6 / 51)$ vs. $12 \%(n=5 / 40) ; p=1)$ and with or without complex reconstruction (respectively, $8 \%(n=2 / 26)$ vs. $14 \%(n=9 / 65) ; p=0.50)$. No association was found 


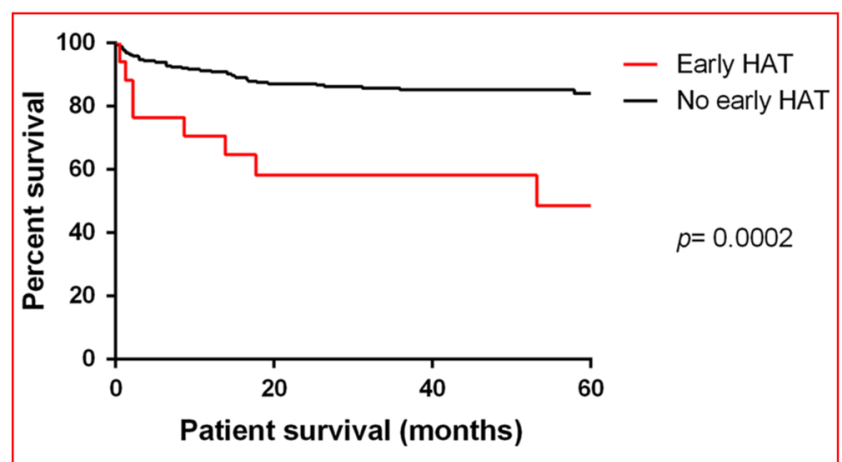

Fig. 1 Patient survival according to early HAT

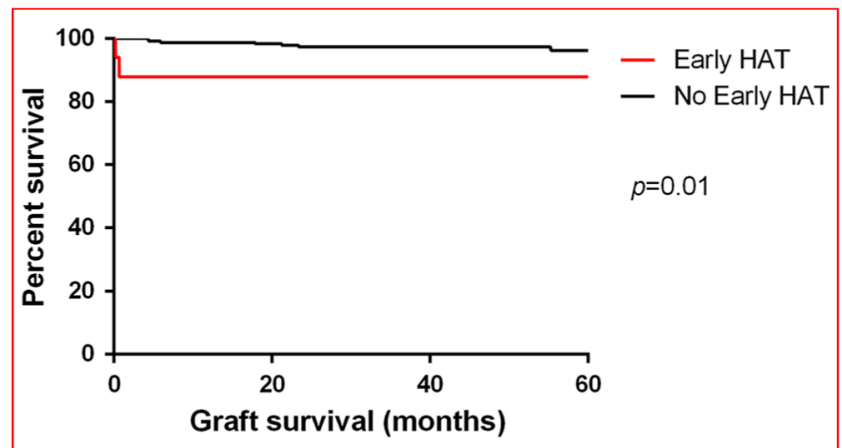

Fig. 2 Graft survival according to early HAT

between the type of donor arterial variation and the occurrence of early HAT.

Concerning recipient arterial sites, the need to use a proximal arterial site (aorta-celiac trunk-splenic artery) was associated with early HAT $(p=0.02)$.

Arterial reconstruction using a long graft artery on distal recipient arterial site (PHA or CHA/GDA bifurcation) was associated with an increased rate of early HAT compared with reconstruction on other sites $(p=0.02)$. No difference was found between recipient sites of implantation when using a short graft artery. In addition, no significant benefit was found in the group of patients who received prophylactic acetylsalicylic acid therapy $(p=0.31)$.

Six variables with $p<0.100$ data on univariate analysis were integrated in the multivariate model and are detailed in Table 4: median recipient age, recipient chronic renal failure, donor arterial variation, donor small artery $(<5 \mathrm{~mm})$, long graft artery and proximal recipient arterial site.

Multivariable logistic regression analysis including the potential confounding factor "donor arterial variation" identified the use of a long graft artery as an independent risk factor associated with early HAT after LT (OR 3.2; $95 \%$ CI $1.2-9 ; p=0.02$ ).

In the group of patients with early HAT, the use of a long graft artery did not decrease the use of retransplantation $(p=0.11)$ and did not improve patient survival $(p=0.09)$ or graft survival $(p=0.22)$.

\section{Discussion}

\section{Statement of the principal findings}

In a cohort of consecutive patients who underwent deceased donor primary LT in the MELD era, we observed an early HAT rate of $6 \%$. This study analyzing the impact of the type of arterial reconstruction on HAT showed that the use of a long graft artery was an independent risk factor of early HAT. In addition, a "long conduit" resulting from the combination of a long graft artery anastomosed on a distal recipient arterial site, as the PHA-CHA/GDA bifurcation, was significantly associated with early HAT. Although the type of arterial reconstruction has already been studied in several series according to the implantation site and is a known HAT risk factor, the length of the donor artery has never been analyzed. We showed in this study that there was no difference between recipient sites of implantation when using a short graft artery in terms of early HAT rate.

\section{Interpretation with reference to the published literature}

The early HAT rate of $6 \%$ and the ratio between early and late HAT are in line with previous reports analyzing HAT occurrence after deceased donor LT [7, 8]. Patients with and without early HAT were comparable on main demographic and operative data and allowed us to focus our analysis on anatomical considerations for arterial reconstruction. Complex arterial reconstruction [21] and pretransplant TACE [7] have been identified as risk factors in previous reports but were not associated with an increased risk of early HAT in the present study. Several reports have shown histological injuries in patients who underwent pretransplant TACE, but these lesions occurred downstream the proper hepatic artery [22], did not seem to increase HAT occurrence and were associated with hepatic artery stenosis [23], as in our report (data not shown).

Two technical approaches are described for arterial reconstruction in clinical practice [24, 25]: either keeping a long graft artery offering a better lumen diameter [7, 26]; or splitting the graft artery to obtain a more anatomical, non-redundant conduit [12, 18]. The first conservative approach should facilitate the management of potential post-LT arterial complications, whereas the latter results in a smaller lumen diameter and potential difficulties in case of reoperation for arterial complications. Our current findings strongly suggest that arterial anastomosis most 
Fig. 3 Types of arterial reconstruction
Short donor artery $(\mathrm{n}=191)$

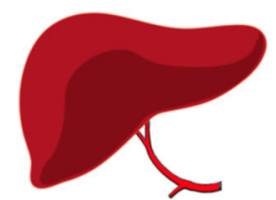

Distal

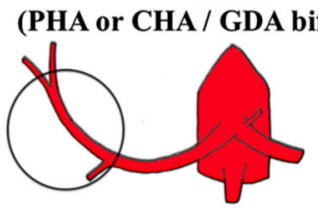

$\begin{array}{lc}\text { Patients n (\%) } & 74(26) \\ \text { HAT n (\%) } & 1(1.4) \\ \text { P Value } & \text { ns }\end{array}$

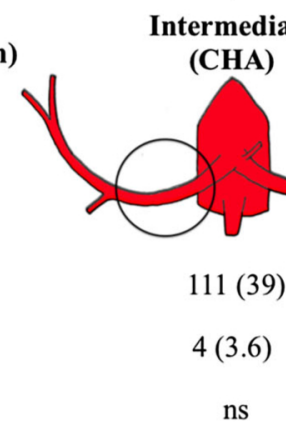

ns
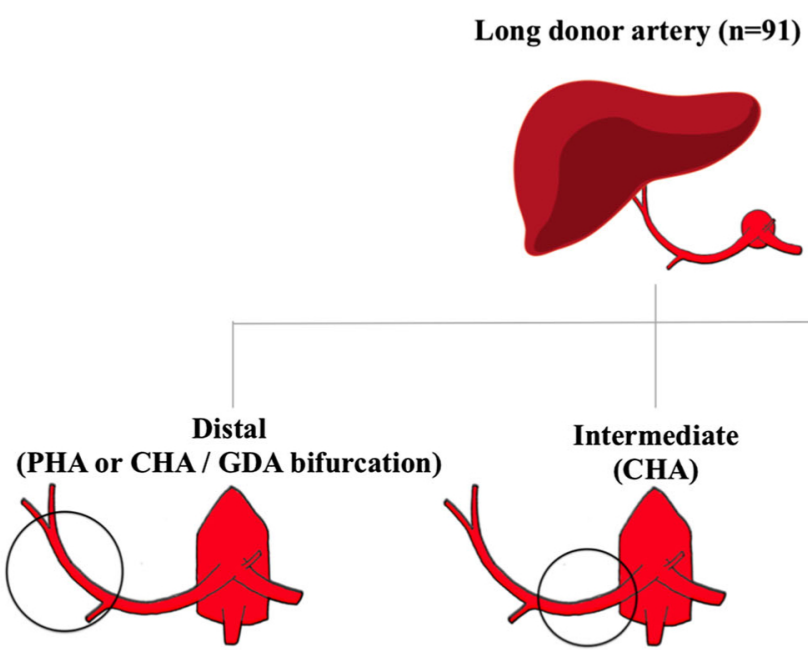

Patients n (\%)

24 (9)

HAT n (\%)

4 (17)

0.02

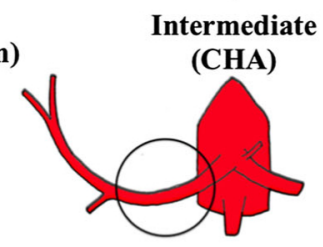

61 (22)

$6(2)$

$5(8)$

2 (33)

ns
Proximal

(CT/SA/Aorta)

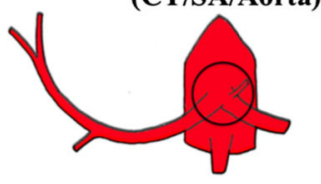

$6(2)$

1 (17)

ns closely restoring normal anatomy is of paramount importance to prevent early HAT.

Although using a long graft artery was associated with arterial anatomical variation as expected (56\%), the negative effect of this type of reconstruction persisted in the subgroup of patients who underwent an anastomosis using a long graft artery without context of replaced arteries (44\%). Merion et al. [27] showed in 1989 that the use of a Carrel patch reduced the occurrence of HAT; this positive effect disappeared when the anastomosis was done on proper hepatic artery. In line with the present study, the risk of HAT was significantly higher with a long conduit resulting from a long graft artery anastomosed on the recipient's proper hepatic artery than on the recipient's common hepatic artery [27]. Our results highlight the need for a compromise between arterial diameter and arterial length according to Poiseuille's law which define the volume flowrate (Volume flowrate $=(\pi$ (Pressure difference) (radius) $\left.^{4}\right) /(8$ (Viscosity) (Length)).

Although many methods have been described to prevent HA kinking, such as omental flap or interposition of hemostatic sealants [25,28], a long graft artery seems to be 
Table 4 Results of multivariate logistic regression analysis for risk factors of early HAT (Hosmer-Lemeshow goodness of fit $p$ value $=0.48)$

\begin{tabular}{llll}
\hline Variables & OR & $95 \%$ CI & $p$ value \\
\hline Recipient age (year) & 1.25 & $1.16-4.12$ & 0.18 \\
Recipient chronic renal failure* & 6.48 & $1.83-22.48$ & 0.10 \\
Donor arterial variation & 2.57 & $0.95-6.94$ & 0.08 \\
Long graft artery & 3.24 & $1.21-8.82$ & 0.02 \\
Recipient site: CT/SA/Aorta & 6.09 & $1.48-25.04$ & 0.27 \\
\hline
\end{tabular}

CT celiac trunk, $S A$ splenic artery

* Creatinine clearance (Cockcroft-Gault) $<60 \mathrm{ml} / \mathrm{min} / 1.73 \mathrm{~m}^{2}$

more exposed to kinking or at least to leukocytes/platelets aggregation, which contributes to reduced arterial flow and thrombus formation. To our knowledge, there is no evidence that using a long graft artery could improve the management of potential post-LT arterial complications. In case of early HAT, no difference was found in patient/graft survivals between patients with long or short graft arteries, suggesting that there is no obvious benefit of using a long graft artery to improve surgical management of potential HAT.

\section{Strength and weakness of the study}

The main strength of this study is the prospective review of arterial reconstructions and the analysis of its impact on early HAT in a large single-center experience in LT. The present study has some limitations. First, this study had a sample size that probably enabled us to show an influence of demographic and other operative factors on HAT occurrence (Type II error $(\beta)$ ). Second, our data indicated that grafts from the recipient's aorta-celiac trunk-splenic artery were significantly associated with HAT, but the small size of this subgroup and potential confounding factors have to be considered (atheromatosis, preoperative recipient arterial dissection justifying this reconstruction in a primary LT). Third, the limited number of patients who developed early HAT does not allow us to conclude on the type of arterial reconstruction that improves surgical management of HAT. These limits highlight the need for further larger multi-center prospective studies.

\section{Conclusion}

This study reports the scope of arterial reconstruction types in a contemporary MELD era cohort and showed that early HAT is still a serious complication after primary LT, affecting graft and patient survival rates. Use of a long graft artery was an independent factor associated with early
HAT and can be a potentially modifiable technical factor. Thereby, we recommend the use of a short graft artery with a direct path when feasible to reduce the occurrence of early HAT after primary liver transplantation.

Authors' contribution AH, RS, EJ and FN designed the paper, reviewed the literature, collected data, wrote the paper and contributed important ideas. GB, HH, HB, FP, JUB, SJ, BG, GPP designed the paper, collected data and contributed important ideas.

\section{Compliance with ethical standards}

Conflicts of interest The authors declare no conflicts of interest.

\section{References}

1. Murray KF, Carithers RL Jr (2005) AASLD practice guidelines: evaluation of the patient for liver transplantation. Hepatology 41(6):1407-1432

2. Schuppan D, Afdhal NH (2008) Liver cirrhosis. Lancet 371(9615):838-851

3. Moon DB, Lee SG (2009) Liver transplantation. Gut Liver 3(3): $145-165$

4. Decaens T (2012) Liver transplantation for hepatocellular carcinoma: time for an international consensus. Clin Res Hepatol Gastroenterol 36(4):316-318

5. Mourad MM, Liossis C, Gunson BK, Mergental H, Isaac J, Muiesan P et al (2014) Etiology and management of hepatic artery thrombosis after adult liver transplantation. Liver Transplant 20(6):713-723

6. Silva MA, Jambulingam PS, Gunson BK, Mayer D, Buckels JA, Mirza DF et al (2006) Hepatic artery thrombosis following orthotopic liver transplantation: a 10-year experience from a single centre in the United Kingdom. Liver Transplant 12(1):146-151

7. Duffy JP, Hong JC, Farmer DG, Ghobrial RM, Yersiz H, Hiatt JR et al (2009) Vascular complications of orthotopic liver transplantation: experience in more than 4,200 patients. J Am Coll Surg 208(5):896-903 discussion-5

8. Chen J, Weinstein J, Black S, Spain J, Brady PS, Dowell JD (2014) Surgical and endovascular treatment of hepatic arterial complications following liver transplant. Clin Transplant 28(12):1305-1312

9. Perez-Saborido B, Pacheco-Sanchez D, Barrera-Rebollo A, Asensio-Diaz E, Pinto-Fuentes P, Sarmentero-Prieto JC et al (2011) Incidence, management, and results of vascular complications after liver transplantation. Transplant Proc 43(3):749-750

10. Tzakis AG, Gordon RD, Shaw BW Jr, Iwatsuki S, Starzl TE (1985) Clinical presentation of hepatic artery thrombosis after liver transplantation in the cyclosporine era. Transplantation 40(6):667-671

11. Bekker J, Ploem S, de Jong KP (2009) Early hepatic artery thrombosis after liver transplantation: a systematic review of the incidence, outcome and risk factors. Am J Transplant 9(4):746-757

12. Dokmak S, Aussilhou B, Landi F, Dondero F, Termos S, Paugam-Burtz $C$ et al (2015) The recipient celiac trunk as an alternative to the native hepatic artery for arterial reconstruction in adult liver transplantation. Liver Transplant 21(9):1133-1141

13. Kirbas I, Ulu EM, Ozturk A, Coskun M, Harman A, Ogus E et al (2007) Multidetector computed tomographic angiography findings of splenic artery steal syndrome in liver transplantation. Transplant Proc 39(4):1178-1180 
14. Dokmak S, Aussilhou B, Belghiti J (2013) Liver transplantation and splenic artery steal syndrome: the diagnosis should be established preoperatively. Liver Transplant 19(6):667-668

15. Starzl TE, Hakala TR, Shaw BW Jr, Hardesty RL, Rosenthal TJ, Griffith BP et al (1984) A flexible procedure for multiple cadaveric organ procurement. Surg Gynecol Obstet 158(3):223-230

16. Addeo P, Souche R, Bachellier P (2015) An alternative technique for harvesting marginal liver grafts with a replaced or accessory right hepatic artery. World J Surg 39(7):1828-1831. doi:10.1007/ s00268-015-3018-4

17. Gordon RD, Shaw BW Jr, Iwatsuki S, Todo S, Starzl TE (1985) A simplified technique for revascularization of homografts of the liver with a variant right hepatic artery from the superior mesenteric artery. Surg Gynecol Obstet 160(5):474-476

18. Scatton O, Sepulveda A, Massault PP, Gouya H, Soubrane O (2009) Reconstruction vasculaire et transplantation hépatique. MC-Techniques chirurgicales-Appareil digestif 1-9 ([Article 40-793])

19. Panaro F, Navarro F (2011) Optimizing outflow in piggyback liver transplantation without caval occlusion: the three-vein technique. Liver Transplant 17(6):742 author reply 3-4

20. Vivarelli M, La Barba G, Cucchetti A, Lauro A, Del Gaudio M, Ravaioli $M$ et al (2007) Can antiplatelet prophylaxis reduce the incidence of hepatic artery thrombosis after liver transplantation? Liver Transplant 13(5):651-654

21. Soliman T, Bodingbauer M, Langer F, Berlakovich GA, Wamser P, Rockenschaub S et al (2003) The role of complex hepatic artery reconstruction in orthotopic liver transplantation. Liver Transplant 9(9):970-975

22. Panaro F, Ramos J, Gallix B, Mercier G, Herrero A, Niampa H et al (2014) Hepatic artery complications following liver transplantation. Does preoperative chemoembolization impact the postoperative course? Clin Transplant 28(5):598-605

23. Goel A, Mehta N, Guy J, Fidelman N, Yao F, Roberts J et al (2014) Hepatic artery and biliary complications in liver transplant recipients undergoing pretransplant transarterial chemoembolization. Liver Transplant 20(10):1221-1228

24. Sulpice L, Desfourneaux V, Rayar M, Meunier B, Lakehal M, Bentabak K, Graba A, Boudjema K (2013) Techniques de transplantation hépatique chez l'adulte. EMC-Techniques chirurgicales-Appareil digestif 8(2):1-27 ([Article 40-790])

25. Panaro F, Bouyabrine H, Carabalona JP, Marchand JP, Jaber S, Navarro F (2012) Hepatic artery kinking during liver transplantation: survey and prospective intraoperative flow measurement. J Gastrointest Surg 16(8):1524-1530

26. Klintmalm GBG, Busuttil RW (2015) Recipient hepatectomy and grafting, Chapter 45. In: Transplantation of the liver, 3rd edn. Elsevier, W.B. Saunders, Philadelphia, pp 600-610

27. Merion RM, Burtch GD, Ham JM, Turcotte JG, Campbell DA (1989) The hepatic artery in liver transplantation. Transplantation 48(3):438-443

28. Panaro F, Bouyabrine H, Carabalona JP, Nougaret S, Jung B, Pageaux GP et al (2014) Omental flap for hepatic artery coverage during liver transplantation. J Gastrointest Surg 18(8):1518-1522 